\section{UN ACERCAMIENTO TEÓRICO A LA ESTRATÉGICA RETÓRICA FEMENINA DE GERTRUDIS GÓMEZ DE AVELLANEDA}

\author{
Brígida M. Pastor \\ ILLA-CCHS, CSIC-Consejo Superior de \\ Investigaciones Científicas, Madrid. \\ brigidam.pastor@cchs.csic.es
}

\section{A THEORETICAL APPROACH TO GERTRUDIS GÓMEZ DE AVELLANEDA'S FEMININE RHETORICAL STRATEGIES}

Cómo citar este artículo/Citation: Pastor, B. M. (2014). "Un acercamiento teórico a la estratégica retórica femenina de Gertrudis Gómez de Avellaneda". Arbor, 190 (770): a186. doi: http://dx.doi.org/10.3989/arbor.2014.770n6007
Copyright: (c) 2014 CSIC. Este es un artículo de acceso abierto distribuido bajo los términos de la licencia Creative Commons Attribution-Non Commercial (by-nc) Spain 3.0.

Recibido: 12 febrero 2014. Aceptado: 30 octubre 2014.

RESUMEN: Este estudio pretende definir y examinar la estratégica retórica femenina de Gertrudis Gómez de Avellaneda. Avellaneda escribió un corpus extenso de poesía, teatro, artículos periodísticos y obras en prosa, pero es en su prosa donde mejor podemos hallar el paradigma de su evolución como literata y como escritora feminista. A través de estas estrategias narratológicas, los personajes de ficción de Avellaneda se crean como figuras de resistencia, reflejando los conflictos personales de la autora como una mujer fragmentada entre su propia identidad y la necesidad de adherirse a las normas culturales. Finalidad última de este estudio es la de investigar cómo las estrategias narrativas y recursos literarios de Avellaneda subvierten y redefinen la tradición textual desde la que su obra ha evolucionado, y forman parte de un importante proyecto que crea un lugar para Avellaneda en la vanguardia de la literatura hispánica del siglo XIX y del pensamiento feminista.

PALABRAS CLAVE: Retórica femenina; Feminismo; Estrategias lingüísticas; Gómez de Avellaneda; Parler-femme.
ABSTRACT: This study aims to define and examine Gertrudis Gómez de Avellaneda's strategic feminine rhetoric. Avellaneda wrote an extensive corpus of poetry, plays, journalistic articles and prose works, but particularly her prose works offer the best paradigm of her evolution as a writer and as a feminist. Through these narratological strategies, Avellaneda's fictional characters are created as figures of resistance, reflecting the author's personal conflicts as a woman divided between her own identity and the need to conform to cultural norms. The ultimate aim of this study is to investigate how Avellaneda's literary devices and narrative strategies subvert and redefine the textual tradition from which her work evolved, and are part of an important project that painstakingly creates a place for Avellaneda at the forefront of nineteenth-century Hispanic literature and feminist thought.

KEYWORDS: Feminine rhetoric; Feminism; Linguistic strategies; Gómez de Avellaneda; Parle-femme. 
Este estudio pretende definir y examinar la estratégica retórica femenina de Gertrudis Gómez de Avellaneda, que contempla tanto aspectos sociales como literarios. Avellaneda escribió un corpus extenso de poesía, teatro, artículos periodísticos y obras en prosa, pero es en su prosa donde mejor podemos hallar el paradigma de su evolución como literata y como escritora feminista. Avellaneda escribió seis novelas: Sab (1841), Dos mujeres (1842), Espatolino (1844), Guatimozín (1846), Dolores (1851) y El artista barquero o los cuatro cinco de junio (1861). Cada una de las seis novelas representa, en mayor o menor medida, una aportación a la problemática del género, pero las dos primeras, Sab y Dos Mujeres y la última, El artista barquero o los cuatro de junio son las más representativas en este sentido. A través de estas estrategias narratológicas, los personajes de ficción de Avellaneda se crean como figuras de resistencia, reflejando los conflictos personales de la autora como una mujer fragmentada entre su propia identidad y la necesidad de adherirse a las normas culturales, como asimismo se revela en su Autobiografía y cartas, publicadas póstumamente en 1907 por la viuda de su amado Ignacio Cepeda Alcalde, destinatario de este extenso epistolario ${ }^{1}$. Finalidad última de este estudio es la de investigar cómo las estrategias narrativas y recursos literarios de Avellaneda subvierten y redefinen la tradición textual desde la que su obra ha evolucionado, y forman parte de un importante proyecto feminista que crea un lugar para Avellaneda en la vanguardia de la literatura hispánica del siglo XIX y del pensamiento feminista.

La obra avellanedina ilustra la trayectoria de la marginación histórico-cultural de la mujer desde su exclusión del discurso hasta la posesión del logos que la habilita para codificar su propia realidad, inscribiéndose en la historia. Objetivo de este estudio, así pues, es explorar la trayectoria de los personajes femeninos como el posible camino por el que transitaron las mujeres en el mundo hispánico en su búsqueda de un sistema escritural capaz de transmitir su historia. El propósito de este proceso es redefinir el signo mujer y proponer un alternativo signo hombre de modo que su auténtica identidad emerja de entre las distorsiones falogocéntricas. Si el lenguaje es el sistema que ordena la realidad social, la incorporación de símbolos renovados debería alterar no solo el lenguaje, sino el orden mismo de la sociedad. Al participar del poder creativo del logos, la mujer deja de ocupar el lugar del Otro, el locus desvalorizado de la cultura, donde es relegada al silencio, al olvido, a ser representada por un discurso ajeno. En vez de ello, la mujer se constituye en el sujeto de su propio discurso. De este modo, el discurso que ha servido para oprimirla, deviene el instrumento más eficaz de su liberación.

Se analiza una selección de las obras de Avellaneda desde una perspectiva teórica de género, estudiando cómo la autora emplea estratégicamente una serie de técnicas narrativas y recursos estilísticos para hacer frente a las normas masculinas y a la auto-representación femenina. Estas estrategias exploran la expresión del principio femenino tanto desde el punto de vista femenino como masculino, y son análogas a la propuesta psico-lingüística del parler-femme de la teórica psicoanalista Luce Irigaray, clave para subvertir la representación social y literaria del género perpetuada por la cultura patriarcal.

El estilo retórico de Avellaneda enmascara una crítica subversiva de las formas de auto-expresión a su disposición como escritora y como mujer, articulando al mismo tiempo su alienación de las defectuosas estructuras sociales. Sus escritos y su propia experiencia vital representan a una mujer que instó a que se produjeran cambios en la situación de la mujer, haciendo de ella una excelente literata y una figura pionera en el feminismo hispánico ${ }^{2}$. La propia vida de Avellaneda fue una constante búsqueda de emancipación personal. Llevó una vida atípica para una mujer de su clase y de su tiempo: desafió la tradición patriarcal, al negarse a un matrimonio concertado, al tener varias aventuras amorosas y un hijo ilegítimo. No solo se rebeló contra los cánones sociales establecidos a través de sus experiencias personales, sino también llenó sus escritos con actitudes y sentimientos que expresan disconformidad con una sociedad represiva y convencional.

Las escritoras como Avellaneda, que en el siglo XIX no se adhirieron a los cánones masculinos de expresión permitidos a su sexo, fueron condenadas y criticadas. Algunos años después de la muerte de Avellaneda, por ejemplo, José Martí, refiriéndose a las poetas de América Latina en sus Obras completas, describió la poesía de Avellaneda como "ruda y enérgica, en contraste con la "poesía femenil de la poetisa cubana Luisa Zambrana más convencional”. Escribió Martí: "Hay un hombre altivo, a veces fiero, en la poesía de Avellaneda: hay en todos los versos de Luisa un alma clara de mujer. [...] No hay mujer en Gertrudis Gómez de Avellaneda. Todo anunciaba en ella un ánimo potente y varonil" (Martí, 1975, pp. 310-311). Martí censura la poesía de Avellaneda por estas cualidades y concluye que sin duda Zambrana es mejor poeta que Avellaneda. Martí masculiniza a Avellaneda con el objeto de rechazar su enfoque poco convencional y liberal. Es interesante observar a través 
de las palabras de Martí las dificultades que Avellaneda debió haber tenido que enfrentar como mujer, ya que no solo transgredió los cánones aceptados de comportamiento femenino, sino también imbuyó sus escritos con las actitudes y los sentimientos no convencionales.

¿Puede Avellaneda ser considerada una escritora feminista ${ }^{3}$ Cuando se utiliza el término "feminismo", es de gran relevancia tener en cuenta los diferentes significados que puede asumir en diferentes contextos. Me adheriré a la definición y metodología de la psicoanalista francesa Luce Irigaray, que considero se acerca más al "feminismo" que Avellaneda expresa en su prosa. Irigaray redefine el término "feminismo" como "un intento de crear un proceso en el que las mujeres (y lo femenino) pueden ser sujetos de su propio discurso, agentes como mujeres" (Whitford, 1991a, p. 129). No hay duda de que la intención de Avellaneda es intervenir como mujer y promover cambios con su escritura. Esta es una postura explícitamente feminista. La imagen de Avellaneda que surge de sus obras en prosa es similar a la expuesta por Margaret Whitford sobre Irigaray:

Quiere convencer a sus lectores, pero también quiere permitir la posibilidad de algo nuevo que surja del diálogo entre ella y sus lectores. En sus textos hay una tensión entre una invitación a crear colectivamente un futuro incierto y un fuerte deseo afirmativo, entre la apertura al otro (mujer) y la auto-afirmación de su propia visión (Whitford, 1991a, p. 24.) [La traducción es mía].

La técnica discursiva de Avellaneda, la manera de expresar su voz femenina dentro de un contexto discursivo patriarcal consiste en convertir un modelo de subordinación en afirmación, comenzando así a transformarlo. Con esta estrategia, se crearon significados, subyacentes al más accesible contenido "público" de sus obras, el uso de estrategias retóricas que pueden parecer "extrañas" en relación con los estándares de lo que conocemos como discurso patriarcal, pero son claramente antecedentes de los elaborados en la teoría psicoanalista de parler-femme de Irigaray. La siguiente cita resume el enfoque general de Irigaray, e ilustra bien el proceso de la evolución de la expresión del feminismo en la prosa de Avellaneda:

El proyecto de utilizar el lenguaje es revelar quién está hablando, a quién, sobre qué, con qué medios. En términos técnicos, esto significa que se trata de una cuestión de desvelar la dinámica de la expresión [énonciation] subyacente a las afirmaciones [énoncés] realizadas. Por debajo de lo que se dice, es posible des- cubrir la materia, la economía de la materia, la energía potencial, las relaciones con el otro y el mundo. El sujeto puede ser enmascarado, enterrado, cubierto, paralizado, o puede ser engendrado, generado, puede llegar a ser, y crecer a través del discurso [en parlant] (Whitford, 1991b, p. 147). [La traducción es mía].

Avellaneda desarrolla una crítica de la estructura del pensamiento patriarcal, así como una reestructuración estratégica de la misma destinada a dar un posible espacio para un imaginario diferente (Whitford, 1991a, p. 103). Para desbaratar la posición de dominio del lenguaje falocéntrico, la mujer precisa forjar una apertura en la textura del discurso filosófico para sacar de ella el significado que le corresponde a la mujer y examinar al mismo tiempo dicho discurso con el fin de exponer su gramática exclusivista, sus configuraciones imaginarias y, sobre todo, para llamar la atención sobre lo que ese discurso no articula, sobre sus silencios (Irigaray, 1996, pp. 74-75).

En los espacios del discurso patriarcal se encuentra la experiencia de la mujer que debe ser recontextualizada en escritos feministas, los que requieren ser descifrados a través de una lectura ginocrítica. Showalter adopta el término ginocrítica para designar el discurso especializado que estudia la psicodinámica de la creatividad femenina, la lingüística y los problemas del lenguaje femenino, la trayectoria individual o colectiva de las escritoras, así como la historia de la literatura, entre otras disciplinas (Showalter, 1977, p. 25). Se propone una política feminista que actuará en dos frentes a la vez - una política "global" que pretende abordar el problema de la opresión universal de las mujeres, y una política "local" que se ocupa de la especificidad y complejidad de la situación particular de cada mujer. Para materializar ambas a la vez, es necesario que las mujeres se unan, para inventar nuevas formas de organización, nuevas formas de lucha y desafíos (Fuss, 1989, pp. 74-75).

Las tres etapas que Elaine Showalter destaca en la obra de la mujer escritora se revelan como eco de las estrategias discursivas y lingüísticas a las que recurre Avellaneda para hacer frente a la situación de la mujer en la cultura y sus intentos de expresar su identidad femenina, mediante la implementación de una forma específicamente femenina de expresión:

Hay una fase prolongada de imitación de los modos existentes de la tradición dominante, y la internalización de las normas del arte y de su visión sobre los roles sociales. En segundo lugar, hay una fase de protesta en contra de estas normas y valores, y la defensa de dere- 
chos y los valores de las minorías, incluida una demanda de autonomía. Por último, hay una fase de auto-descubrimiento, la interiorización, libre de algunas de las dependencias de la oposición, una búsqueda de identidad (Showalter, 1977, p. 13) [La traducción es mía].

La obra de Avellaneda se adhiere a este concepto de evolución feminista. Como ha señalado Beth K. Miller, "en muchos sentidos Avellaneda parece haberse visto a sí misma como los críticos lo han hecho, es decir, ella era consciente de ser una mujer escritora, y a pesar de las circunstancias adversas a las que se enfrentaba, a menudo veía su propia vida y más tarde sus obras como ejemplo, sobre todo, [...] para otras mujeres" (Miller, 1983, p. 203). Phyllis Zatlin Boring traza paralelos entre la autobiografía de Avellaneda y la de contemporáneas feministas norteamericanas - que estaban escribiendo confesiones introspectivas y luchando por la igualdad de las mujeres, tanto en la escritura como en la acción política - y ve la lucha de Avellaneda en términos claramente feministas: "Avellaneda [...] seguramente no cabía en el patrón femenino tradicional que la sociedad le tendió y ella se daba cuenta de la gran diferencia entre lo que era de veras y lo que toda mujer [...] debía ser" (Zatlin, 1981, p. 94). Críticos que abordaron el tratamiento de las mujeres en la obra avellanedina, como Beth K. Miller, Phillys Zatlin Boring, Lorna V. Williams, Josefina Inclán, Nelly E. Santos y Alberto J. Carlos, dedicaron sus estudios exclusivamente a los diversos estereotipos femeninos que aparecen en la prosa de Avellaneda. Se concentraron en las representaciones de Avellaneda de solteronas frustradas, esposas desilusionadas, amantes, entre otras, creando clasificaciones de diferentes grados de opresión femenina. Sin embargo, centrarse solo en la caracterización de esta manera para demostrar el grado de opresión de la mujer bajo el patriarcado es alejarse de la relación entre ficción y realidad. Como Toril Moi destaca al referirse a esta práctica:

Estudiar "imágenes de mujeres" en la ficción es equivalente al estudio de imágenes falsas de las mujeres en la ficción escrita por ambos sexos. [...] La escritura es vista como una reproducción más o menos fiel a una realidad externa a la que todos tenemos acceso equitativo e imparcial, y que por lo tanto nos permite criticar al autor según el criterio de que él o ella ha creado un modelo incorrecto de la realidad que de alguna manera todos conocemos (Moi, 1985, pp. 44-45). [La traducción es mía].

Avellaneda, como mujer escritora, estaba atrapada entre una impositivista sociedad falocéntrica y su necesidad, como mujer, de convertirse en sujeto de su propio discurso por derecho propio. Gilbert y Gubar explican cómo la escritora se ve obligada a recurrir a un conjunto de metáforas, no solo para reflexionar, sino para desafiar la estructura misógina de la cultura occidental. Por lo tanto, la escritora tiene que ser "femenina", mientras niega su auténtica identidad femenina; ella crea un mundo de mujeres en sus novelas, pero, al mismo tiempo, rechaza ese mundo por el simple acto de "llegar a ser" una novelista, al tomar la pluma, un objeto al que Gilbert y Gubar se refieren como el "pene metafórico" - una herramienta definida esencialmente "masculina" que ha sido considerada no solo inadecuada sino también ajena a las mujeres (Gilbert y Gubar, 1979, p. 12). De acuerdo con este análisis, la escritura de Avellaneda se puede leer como un discurso de doble voz, que contiene una historia "dominante" y otra "silenciada", y que se le denomina "palimpsesto" (Showalter, 1977, p. 264).

La metodología de Gilbert y Gubar en su estudio The Mad Woman in the Attic considera que "la experiencia genera metáfora y la metáfora crea la experiencia en relación con los estereotipos femeninos" (Gilbert y Gubar, 1979, p. 13). Aunque Avellaneda utiliza diferentes tipos de caracterización para describir la posición de las mujeres en el patriarcado, se recurre inevitablemente a las imágenes estereotipadas de la solterona frustrada, la esposa desilusionada y la femme fatale. En el análisis de Gilbert y Gubar, estos estereotipos sirven de paralelos a sus construcciones del "ángel de la casa" y la "loca en el ático", respectivamente. Estas críticas sostienen que esos estereotipos se han convertido en imágenes fijas en la caracterización tanto de escritores como de escritoras, y defienden que es una batalla constante para las mujeres escritoras crear definiciones alternativas de las mujeres. Sin embargo, el análisis de la asimilación y la transgresión de las imágenes de "ángel" y "monstruo" que el canon patriarcal había generado para la mujer es elocuente en sus novelas Dos Mujeres y El artista barquero. Por ejemplo, en Dos mujeres, esta dicotomía cultural queda ilustrada en el dilema que el protagonista masculino, Carlos, experimenta por las dos mujeres que ama, Luisa y Catalina. Carlos recurre al mecanismo de autodefensa al idealizar a Luisa (el "ángel”) como "un aura de pureza" y condena a Catalina (el "monstruo") como "un cerco de llamas que punzan y devoran" (Avellaneda, 18691871, t. IV, p. 47). Estas discordantes imágenes femeninas en la psique de Carlos son una clara ilustración de la tesis de Simone de Beauvoir, que la mujer representa los sentimientos ambivalentes del hombre sobre "su propia incapacidad de controlar su propia existencia física, su propio nacimiento y su propia muerte" [La traducción es mía] (citado por Gilbert y Gubar, 1979, p. 
34). En muchas ocasiones, Avellaneda intenta "matar" el "ángel de la casa" y también logra hasta cierto punto que el "monstruo" colapse [La traducción es mía] (Gilbert y Gubar, 1979, p. 17). En Dos mujeres, el personaje transgresor de Catalina, definido culturalmente como un "monstruo", al final sucumbe a las leyes sociales, suicidándose. Por su parte, el otro personaje femenino más convencional, Luisa, representa el estereotipo de "ángel", y decide quedarse con su marido, a pesar de su infelicidad y falta de realización personal, dejándose vencer por las normas culturales.

En sus escritos, Avellaneda también tuvo que desafiar la imagen de "monstruo" que ella misma representa para el orden patriarcal, ya que, en palabras de Anne Finch, "que una mujer tome la pluma era monstruoso y presuntuoso" (citado por Gilbert y Gubar, 1979, p. 32). En la tradición de las letras cubanoespañolas, dominada exclusivamente por hombres, la labor a la que se enfrentaba una mujer escritora como Avellaneda fue realmente desafiante. A través de su intensa carrera que se inicia en 1841 hasta su muerte en 1873 , luchó por encontrar un espacio propio dentro de la dominante (y masculina) tradición literaria, hostil a las mujeres, y por construir nuevas definiciones del sujeto femenino en la ficción (Pastor, 1995c, p. 248).

Avellaneda articula un lenguaje que representa la posibilidad de un discurso diferente - no masculino-, en otras palabras, un lugar para el "otro" como femenino en el lenguaje. Esta "retórica femenina" o parler-femme tiene la misión de producir, por tanto, un discurso en el que la mujer pueda ser sujeto, permitiéndole entablar un diálogo de igualdad con el hombre, en condiciones de igualdad, aunque con una base diferente (Whitford, 1991b, pp. 137-138). En su definición de parler-femme, Irigaray hace hincapié en dos puntos: en primer lugar, no es una cuestión de escritura femenina, sino la respuesta a otro interlocutor, por lo que la mejor analogía es la situación experimental del psicoanálisis, donde la dinámica entre el discurso y la respuesta es identificada directamente; en segundo lugar, no es una cuestión de un discurso biológicamente determinado, sino de la identidad cultural, adoptada en el discurso dentro de un sistema patriarcal simbólico, en el que la única posible posición de sujeto es masculina. Dentro de este sistema, la única identidad femenina concedida a las mujeres es con carácter defectuoso o inferior. Así, las mujeres carecen simbólicamente de autodefinición.

En contraste con el metalenguaje masculino (Iangue), que se basa en las normas y estructuras formalizadas, la retórica femenina de Avellaneda se refiere a una forma más abierta y fluida de lenguaje, que puede transmitir pensamientos y sentimientos de una forma más específicamente femenina. Por su propia naturaleza, parler femme es un lenguaje que se resiste a la definición, no tiene "metalenguaje". Este "estilo", o "escritura", de las mujeres es siempre fluido, "sin dejar de lado las características de los fluidos que son difíciles de idealizar" y que resiste y explota toda forma, imagen, idea o concepto firmemente establecido. En parler-femme, tanto el inconsciente como el género pueden expresarse con más precisión.

Cabe destacar que parler femme no es un concepto exclusivamente psico-lingüístico, sino que se refiere al verdadero dilema que sufren las mujeres cuando se las fuerza a adoptar el papel de objeto en el orden falocéntrico (Whitford, 1991b, pp. 137-138). Su reto es entrar en el lenguaje como sujetos con pleno derecho y crear un lenguaje, que es una representación válida de su genealogía. Implícito en este concepto está la necesidad de las mujeres de permanecer fieles a su genealogía femenina y preservar su vínculo con la madre y, como Avellaneda, se plantea la idea de una genealogía femenina, que se engendra a través del lenguaje, sin abogar por la invención de un nuevo lenguaje para este fin, sino más bien por la manipuladora destreza de la retórica convencional (masculina) con el fin de crear un nuevo estilo e identidad (femeninos). Esta fidelidad a la genealogía femenina se descubre elocuentemene en su novela Sab. El personaje de Teresa se muestra en conexión con la línea femenina de la madre, como lo revelan sus palabras a Carlota: "Debemos Ilorar eternamente una pérdida que nos privó, a ti de la mejor de las madres, a mí, pobre huérfana desvalida, de mi única protectora" (Gómez de Avellaneda, 1973, p. 143). Los términos "Ilorar", "pérdida", "desvalida", "única protectora" sugieren su concientización y vulnerabilidad como mujer en la cultura patriarcal. El reconocimiento de Teresa de su deuda con su madre adoptiva, e indirectamente con la genealogía femenina, sienta las bases de su evolución en la toma de conciencia de sí misma y su triunfo en la cultura y el discurso.

De este modo, la retórica femenina de Avellaneda representaría una "casa de lenguaje" que permite a las mujeres ocupar un espacio, aunque sea provisionalmente, para sí mismas en el orden simbólico masculino, para expresar su propia y autónoma identidad. Este estilo o langage (femenino) permite a la mujer articular su posición y condición ambivalentes en la cultura, y por lo tanto en el imaginario cultural (masculino). Es solo en el momento de convertirse en sujetos agentes de su propio discurso que una mujer puede expresar su verdadera identidad, así como su relación con la ge- 
nealogía femenina representada por su madre y otras mujeres - que en términos irigarayanos se define como "pago de la deuda a la madre" ["paying the debt to the mother"] (Irigaray, 1993, p. 16). Si la mujer continúa silenciada, solo le queda la alternativa de expresar su identidad a través de síntomas somáticos, convirtiéndose en una histérica (Whitford, 1991b, p. 77). Avellaneda plasma las reacciones histéricas en varias de sus figuras femeninas cuando son incapaces de superar la represión de las normas patriarcales. La histeria de Avellaneda queda elocuentemente expresada en sus propias reacciones a su amado Cepeda en Autobiografía y cartas. En varias ocasiones, Avellaneda pone de relieve el malestar en su cuerpo - un síntoma característico de las enfermedades relacionadas con la histeria, a menudo consideradas como condición estereotipada de la mujer. Sin embargo, se trata de una histeria combativa, en lugar de la tradicional ecuación (masculina) de la feminidad pasiva con la histeria: "Yo me encuentro bastante embromada con males de estómago y un histérico que me devora. Paso muchos días en cama poseída de tristeza y fastidio insoportable" (Gómez de Avellaneda, 1914 , p. 101) o más adelante: "No me haga caso: tuve jaqueca a media noche y creo que me ha dejado algo de calentura: ¿no es verdad? mi cabeza no está en su ser natural" (Gómez de Avellaneda, 1914, p.119). Estos malestares físicos son al mismo tiempo una estrategia, además, que libera a Avellaneda de las normas su interlocutor masculino, Cepeda, convirtiendo así su discurso en un acto subversivo. Al inscribir el cuerpo de la mujer, esta estrategia contrarresta el monopolio exclusivo del discurso dominante, aunque sea solo temporalmente. La histeria de Avellaneda es una reacción a las expectativas de Cepeda (y de la sociedad patriarcal) de sumisión e infravaloración femenina que resultan en definiciones patriarcales extremas e irreales de "feminidad". Esta referencia a la naturaleza física del cuerpo femenino es paralela a las muchas referencias a la enfermedad en la literatura femenina. Gilbert y Gubar expanden sus reflexiones sobre la batalla de las escritoras con el pasado para incluir la prevalencia de la enfermedad en la literatura por mujeres y sobre mujeres:

Surrounded as she is by images of disease, traditions of disease, and invitations both to disease and to dis-ease, it is no wonder that the woman writer has held many mirrors up to the discomforts of her own nature. (Gilbert y Gubar, 1979, p. 57).

La necesidad de una forma específica de lenguaje femenino deriva de la meta que se impone Avellaneda: la igualdad y diferencia entre los géneros. Según su planteamiento teórico, lo femenino en el lenguaje y en el discurso cultural ha estado tradicionalmente absorbido por lo masculino. Su énfasis en la diferencia, y en particular la diferencia sexual, puede ser considerada como una respuesta a este hecho. Avellaneda no cree que la igualdad se pueda lograr mientras las mujeres sigan siendo objetos de intercambio dentro de un imaginario cultural masculino, pero sí cuando las mujeres se conviertan en sujetos de su propio discurso (Whitford, 1991b, p. 131). Una auténtica voz femenina adoptará una perspectiva específicamente femenina que expresará su posición y condición en la cultura, y al mismo tiempo trascenderá y tratará de cambiar los códigos de la cultura patriarcal. El patriarcado, o "cultura-entre los hombres" (también denominada cultura "mono-sexual / hom(m)o-sexual)", es una construcción histórica y, como tal, está sujeta a cambio (Irigaray, 1993, p. 86).

La retórica femenina de Avellaneda exige un cambio en este sistema, de lo contrario las mujeres seguirán siendo absorbidas por los hombres en el orden falocéntrico dominante y así excluidas como sujetos culturalmente válidos y creativos. Desde una perspectiva psicoanalítica se mantiene que el espejo metafóricamente no refleja la imagen auténtica de la mujer, sino la figura construida por las expectativas culturales patriarcales, reflejo en el que la verdadera imagen de la mujer está ausente. De allí nace su necesidad de llenar con palabras el vacío del espejo para completarse, para traducirse a sí misma (Agosín, 1984, p. 221).

Un aspecto fundamental sobre esta necesidad de la mujer para moverse libremente, es la capacidad de manipular el lenguaje, permitiendo así que la mujer utilice un irreductible y exclusivo langage femenino. El propósito de Avellaneda es la superación de la ideología masculina que la identifica como el sexo inferior y la define exclusivamente como objeto del imaginario del sujeto masculino. Avellaneda propone una serie de estrategias que permiten que la mujer se inserte a sí misma en el discurso masculino como una auténtica voz femenina, y que reflejan aquellas a las que recurre Avellaneda en su prosa. Una de estas estrategias es la "sintaxis doble", una estrategia que libera al lenguaje convencional (masculino) de las estructuras sintácticas estáticas que otorgan autoridad al hombre -el sujeto (hombre) y el objeto (mujer) están en una relación fosilizada, que aparentemente constituye una verdad universal (Irigaray, 1993, p. 190). Avellaneda recurre a este recurso estilístico que revela el diálogo bidireccional entre los géneros, entre emisor y receptor, es el concepto irigarayano de "intercambio amoroso", que es una forma lingüística de expresar una relación fe- 
cunda y creativa entre iguales, de reconocimiento recíproco. En este encuentro de los dos géneros, la mujer, como el hombre, puede ser sujeto, con deseos propios, y no objeto de intercambio. En Dos mujeres, en el encuentro inicial de la transgresora Catalina con Carlos se descubre un "intercambio amoroso", en el que hay un reconocimiento mutuo como iguales de una manera fértil y equilibrada: Carlos valora la "imaginación", "sagacidad", "pensamientos", "versatilidad" e "independencia" de Catalina, transmitiendo una visión positiva del principio femenino e implícitamente reevaluándolo culturalmente (Gómez de Avellaneda, 1869-1871, t. II, pp. 131-132). La admiración de Carlos por su intelecto e independencia transgreden el estereotipado modelo -basado en la belleza y la sumisión - como atributos femeninos de atracción masculina.

La mujer-como-sujeto de Avellaneda debe resistir los intentos de la cultura patriarcal de silenciarla. Otra forma eficaz para mantenerse en un papel agente es utilizar la estrategia de "mimesis" (Whitford, 1991b, p. 132). Según esta táctica discursiva, la visión misógina y estereotipada de la mujer, que se ha diseñado para suprimir su voz es deliberadamente apropiada con el propósito de ser repetida y parodiada, de tal manera que la auténtica visión femenina pueda revelarse. En El artista barquero, el personaje de la sirvienta Niná se proyecta como una mujer sabia, que ha aprendido a sobrevivir en un ambiente opresivo. A modo de superar una orden represora que le da su dueño $M$. Caillard, Nina le contesta irónicamente: “-Bien sabe el señor, contestó ella, - eludiendo tan directa interpelación, - que esta casa es un convento donde no entra jamás alma viviente" (Gómez de Avellaneda, 1869-1871, p. 39). El énfasis retórico que se desprende de "eludiendo tan directa interpelación" pone de manifiesto como ella es consciente de su auténtica identidad, pues parece estar imitando la identidad cultural que se espera de ella como sumisa e inferior. Claramente Nina representa la sabia figura maternal que escapa a las fronteras patriarcalmente definidas.

Las estrategias sofisticadas e indirectas que recorren los escritos de Avellaneda se descubren como necesarias para que las mujeres expresen su identidad en el discurso, no solo porque son reprimidas por la cultura, sino también porque las mujeres tienen poco sentido inherente de sí mismas. La proyección tradicional de la mujer solo tiene una imagen de sí misma que se reduce a la de un mero cuerpo físico-sin poseer una imagen "divina" de sí misma. Avellaneda recurrentemente hace hincapié en la importancia de la divinidad de la mujer: "La Divinidad es lo que necesitamos para llegar a ser libres, autónomas y soberanas [...]. Es esencial que seamos Dios para nosotras mismas para que podamos ser divinas para el otro polo opuesto de la vida y el discurso, no ídolos, fetiches, símbolos que ya han sido definidos o determinados" (Irigaray, 1993, p. 62). [La traducción es mía]. Así, el mismo personaje de Nina en El artista barquero representa claramente la figura divina-maternal que puede moverse libremente más allá de los límites patriarcalmente definidos, y de acuerdo con la estrategia irigarayana de "mímesis", por tanto, puede tener una posición alienada y marginal, pero móvil, a mitad de camino entre las esferas divinas y humanas.

En la cultura patriarcal, a la mujer solo se le ha concedido la función divina como el seno virginal, madre de Dios que engendra al hijo hombre de Dios, sin tener una genealogía femenina propia. Por lo tanto, la línea madre-hija aún no está definida, lo que debilita su poder simbólico. Así desde una perspectiva psicoanalítica se arguye que la mujer necesita un Dios a través del que alcanzar su potencial como ser humano, su verdadera identidad como humano-divina, capaz de crecer-implícitamente en dirección a Dios-un concepto que es desarrollado elocuentemente en la obra de Avellaneda. La mayor parte de sus personajes de ficción femeninos o feminizados (por ejemplo, $\mathrm{Sab}$ ) encarnan en diferentes momentos de su desarroIlo, un grado de divinidad en ellos. Esta culminación se revela cuando los personajes alcanzan un elevado grado de conciencia de sí mismos, generado por la interacción de su participación en el mundo real y sus propios sentimientos internos. Esta comunión conlleva "plenitud", o la unidad con Dios, y el amor concomitante de uno mismo (que psicoanalistas como Jung creen que es esencial para el desarrollo de una personalidad plena). Avellaneda pone de relieve cómo el logro de la "plenitud" de la mujer en la cultura se encuentra en desventaja con respecto al del hombre, que ha alcanzado su estatus cultural superior por medio de su vínculo con un Dios de género masculino, e insta a la necesidad de reconocer a la mujer como un ente divino, es decir, el reconocimiento de su identidad completa: "Si [la mujer] va a convertirse en una mujer, si va a alcanzar su subjetividad femenina, la mujer necesita un dios que actúe como modelo para la perfección de su subjetividad" (Irigaray, 1993, p. 69). [La traducción es mía].

Al no lograr la conexión con estas relaciones fundamentales, lo maternal femenino ha resultado "en encarnaciones parciales y monstruosidades femeninas, o incluso masculinas" (Irigaray, 1993, p. 58). El 
unilateral imaginario (patriarcal) ha dividido la imagen de la mujer por una parte, en una figura monstruosa (o mujer definida por sí misma), y, por otra, en el estereotipo femenino-maternal y culturalmente divino (o mujer definida por el patriarcado). Por lo tanto, el objetivo de la mujer es lograr una identidad genuinamente femenina que sea diferente, pero igual a su contraparte masculina, en lugar de una imagen femenina "irreal", que es meramente un reflejo y proyección de la mirada reductora del sujeto masculino (Irigaray, 1993, p. 171).

En Dos mujeres, la relación de Carlos con Catalina, una mujer con identidad (femenina) propia, es utilizada por la voz narrativa para poner de relieve la represión del principio femenino en la psique masculina. Por un lado, Carlos se mueve y se siente atraído por el "talento y la magia de su conversación, pero, por otro, se siente asustado por el "raciocinio de su razón implacable" (Gómez de Avellaneda, 1869-1871, t. II, p. 124). Mientras que en contacto con Catalina, él puede sentir admiración por ella, cuando está solo, se siente "agitado y descontento", y su reductora mirada (masculina) le lleva a desconfiar de ella y verla como una "mujer horrible", que encarna la idea de la imagen femenina culturalmente temida (Gómez de Avellaneda, 1869-1871, t. II, p. 125). El hecho de que Carlos sienta "dolorosa admiración" por la autenticidad femenina encarnada por Catalina sugiere que la demonización de Catalina, como su idealización de Luisa, tienen una función represiva (Gómez de Avellaneda, 1869-1871, t. II, p. 134).

Asimismo, en El artista barquero, la voz narrativa pone considerable atención al constante estado de "desconcertado" de Huberto, "sin saber lo que le pasaba", "con sorpresa'" e "inexplicables emociones" (Gómez de Avellaneda, 1869-1871, t. IV, pp. 128-29). A veces, la astucia de Madame Pompadour hace que Huberto la admire en la medida en que su fascinación y debilidad lo convertirían en un "esclavo" y "vencido" para siempre (Gómez de Avellaneda, 1869-1871, t. IV, p. 129). La única solución que puede concebir Huberto es escapar de la "sirena peligrosa", y por lo tanto de su inconsciente y de lo femenino (Gómez de Avellaneda, 1869-1871, t. IV, p. 129). La definición de la voz narrativa de Pompadour como "sirena peligrosa" se convierte en eco de la percepción deformada que Huberto tiene de ella, ante quien se siente abrumado e inferior. Curiosamente, de forma similar, Huberto llega a los extremos en la idealización patriarcalizada de su amada Josefina: "con su frente de virgen, que parece trono del candor; con su mirada acariciadora, que era a mi juicio, el espejo de un alma toda amor; con su sonrisa franca y apacible, que solo indica bondad de corazón y nobleza de carácter" (Gómez de Avellaneda, 1869-1871, t. IV, p. 46). Como un hombre en la cultura patriarcal, opta por concebir a la mujer como una idealización maternal femenina, más que como una mujer que se define a sí misma y que representa para él castración y muerte.

La mujer en la cultura patriarcal carece de su propio espejo: "Nos vemos a nosotras mismas en el espejo para complacer a alguien, rara vez para interrogar el estado de nuestro cuerpo o nuestro espíritu, en raras ocasiones para nosotras mismas y en busca de nuestra plenitud" (Irigaray, 1993, p. 65). El concepto del espejo y su poder de deformación en la definición de la subjetividad femenina es un tema recurrente tanto en las novelas como en los escritos autobiográficos de Avellaneda. Avellaneda, defiende que la mujer se encuentra atrapada en el espejo masculino y necesita estratégicamente crear un espejo propio, que refleje una imagen más real de sí misma. En suma, la "otra mujer" de Avellaneda (en otras palabras, la mujer definida por sí misma) se inscribe a sí misma (como Avellaneda en su Autobiografía y cartas, y al igual que varios de sus personajes de ficción) en el discurso (patriarcal) existente. Por ejemplo, en un momento de la narrativa de El artista barquero, Pompadour se mira en el espejo con la esperanza de ver algo detrás de su superficie, pero no puede alterar su inevitable destino cultural, arrebatándola la frustración y la "monstruosidad": "al observar en el espejo su desmejoramiento lastimoso", la voz narrativa describe el poder de la deformación del espejo, proyectándola con una imagen en discordia con lo que realmente Pompadour representa (Gómez de Avellaneda, 1869-1871, t. IV, p. 167).

La apropiación de la voz femenina de un acto que está culturalmente vinculado con la cultura masculina, a modo de inscripción, inserción- "penetración"puede ser considerada como otra táctica por la que la mujer adopta e imita el comportamiento del poder hegemónico masculino. Sin embargo, como señala Irigaray, esto se lleva a cabo de una manera subversiva desde dentro del discurso masculino, demoliendo así astutamente las estructuras defensoras construidas para resistir cualquier intento de destrucción (Irigaray, 1996, p. 88). Por todo ello, la escritura de Avellaneda se caracteriza por el carácter indirecto de su estilo, y su implícito objetivo es superar la ideología masculina que intenta reducir a la mujer a una posición inferior en la cultura, haciendo de ella un objeto del imaginario masculino y negándole su genuina identidad femenina. 
La importancia de la escritura como vehículo subversivo se acentúa si tenemos en cuenta que Avellaneda fue víctima por haber cometido el "pecado" de escribir. Como la mayoría de las mujeres en la cultura patriarcal, la autora debió experimentar su género como un obstáculo doloroso, o incluso una insuficiencia debilitante. A pesar de haber sido una escritora de éxito en su época, Avellaneda sufrió mucha discriminación en un mundo de exclusivo dominio masculino. En la cúspide de su carrera literaria, en 1853, la autora solicitó un puesto vacante en la Real Academia Española y fue rechazada por la única razón de ser mujer. Como la escritora Cecilia Böhl von Faber (Fernán Caballero), contemporánea de Avellaneda, destacaría en una carta dirigida a D. Manuel Cañete y D. José Fernández Espino en 1855: "No hay un pantalón que no se crea, en materia de escribir, superior a todas las enaguas" (Caballero, 1922, p. 30). En un artículo, Avellaneda hace las siguientes observaciones acerca de la discriminación contra la mujer, haciéndose eco de su experiencia personal a manos de la anti-femenina Real Academia:

Si la mujer [...] aún sigue proscrita del templo de los conocimientos profundos, no crea en sí tampoco que los datos de muchos siglos de aceptación en el campo literario y artístico: jah! iNo! también este terreno le ha sido disputado palmo a palmo por el exclusivismo varonil, y aún hoy día sí la mira en él como intrusa y usurpadora, tratándosela, en consecuencia, con cierta ojeriza y desconfianza, que se echa de ver en el alejamiento en que sí la mantiene de las academias barbudas [énfasis de Avellaneda] (Gómez de Avellaneda, 1860, p. 303).

Estas palabras demuestran el machismo obstinado de la mayoría de los miembros de la Academia. La autora consideró que ella era víctima de un código discriminatorio de admisión, simplemente, según ella, por su falta de "barbas". Este incidente despertó en ella una expresión más abierta y combativa del feminismo, que se había expresado muchas veces en secreto y de forma "convencional" a través de sus personajes de ficción. Este episodio estimuló a Avellaneda a promulgar abiertamente sus ideas emancipadoras en la revista literaria Álbum Cubano, que ella fundó y editó después de su regreso a Cuba en 1860. En los doce números que publicó la revista, incluyó sus polémicos artículos "La mujer", en los que Avellaneda expone argumentos deliberada y abiertamente para demostrar los méritos de su sexo, y exigiendo el derecho a la igualdad; incluso expresa la superioridad del talento e intelecto de las mujeres: "Intentamos probar-no ya la igualdad de los sexos-sino la superio- ridad del nuestro" [énfasis de Avellaneda] (Gómez de Avellaneda, 1860, p. 297). El hecho de que la revista sobreviviera poco tiempo es una prueba más de que el enfoque más encubierto era de hecho la forma más eficaz de expresar su feminismo, como sugieren las estrategias narratológicas más sofisticadas que utilizó en El artista barquero, publicado un año más tarde.

Los esfuerzos de Avellaneda por desarrollar plenamente su crítica cultural fueron constantemente frustrados por la sociedad que atacó. Tanto su novela Sab como Dos mujeres fueron prohibidas en Cuba; la primera porque se consideraba que era portadora de un contenido inmoral, con doctrinas subversivas que criticaban el sistema de la esclavitud en Cuba y, por lo tanto, las costumbres imperantes y la segunda como un peligro para la moral de la sociedad (Cruz, 1973, p. 140). No deja de ser paradójico que Avellaneda excluyera estas dos novelas de la última edición de sus Obras literarias en 1869-1871, quizás porque se sentía obligada a hacerlo frente al constante oprobio cultural. Como declarara Avellaneda en una carta dirigida a Cepeda: "Estoy cansada del mundo, de los obsequios, de las calumnias, de la gloria y hasta de la vida" (Gómez de Avellaneda, 1914, p. 175). El que estas dos primeras novelas fueran excluidas de sus Obras literarias se explica principalmente porque Avellaneda creía que su mensaje, evidentemente inconformista, sería perjudicial para la aceptación de su publicación, ya que confiaba que estas obras supondrían su definitiva consagración como autora canónica.

Avellaneda era consciente de que tanto Sab como Dos mujeres estaban lejos de adherirse a los gustos y los cánones de la sociedad de su tiempo, precisamente porque ambas obras intentaron avanzar su propia ideología feminista. Aunque la táctica de excluir estas dos novelas también habría ayudado a mantener un número más amplio de lectores, parece poco probable que Avellaneda pudiera aceptar por mucho tiempo la derrota impuesta por el implacable sistema social que intentaba denunciar en su obra. Sin embargo, en las últimas etapas de su carrera literaria, Avellaneda aprendió una dura lección, que para sobrevivir como escritora tendría que encontrar un compromiso entre la rebeldía y la conformidad estratégica con las normas sociales, y así evitar que ella se convirtiera en objeto de censura y ridículo. En general, todos los escritos de Avellaneda dan testimonio de su profundo y constante interés en la injusta posición de la mujer en la sociedad. Las palabras de Nara Araújo sobre Avellaneda resumen perfectamente la importancia que la figura femenina tenía para la escritora: 
Peregrina es el pseudónimo literario que Gertrudis Gómez de Avellaneda escogió para sí. Peregrina [...] en sentido figurado significa extraña, especial y rara, extraordinaria o insólita. Este acto de bautismo revela la autoconciencia en la escritora de su condición diferente. Diferencia [...] que proyectó desde la perspectiva de género para alcanzar un cuestionamiento de la iniquidad humana (Araújo, 1997, p. 48).

\section{CONCLUSIÓN}

Como mujer escritora en el siglo XIX, para Avellaneda el escribir representa en sí un acto revolucionario, puesto que según la tradición Freud/Lacan, la mujer esencialmente se encuentra fuera de lo Simbólico, o sea desprovista de lenguaje. Dadas estas circunstancias, Avellaneda confronta el dilema de no solo qué escribir, sino también cómo escribir, puesto que la experiencia femenina ha sido tradicionalmente percibida como carente de valor y el sistema discursivo necesario para inscribirse en la historia es precisamente el medio a través del cual ella ha sido alienada. Es evidente a través del análisis de su prosa que Avellaneda tuvo que subvertir estratégicamente la política del lenguaje, socavar la autoridad falogocéntrica, reestructurar el canon que entronizaba al hombre, para así codificar un mensaje diferente. Los recursos retóricos que utiliza Avellaneda incorporan renovados símbolos, alterando el lenguaje y el orden mismo de la sociedad. De este modo, su escritura redefine el signo mujer de modo que su auténtica identidad emerja de entre las distorsiones falogocéntricas. Así el discurso que ha servido para oprimirla, deviene el instrumento más eficaz de su liberación.

De la exploración teórica de la obra seleccionada de Avellaneda se deduce que la lectura de los textos aparentemente falocéntricos no debe ser utilizada para definir la identidad de la mujer, sino para poner en evidencia los códigos culturales que el aparato falocrático ha construido para oprimirla. Se desvela que la mujer ha sido deformada por mitos y estereotipos que la idealizan o hacen de ella un monstruo, que así como le dan la vida poseen la autoridad de quitársela. Todas estas manifestaciones forman parte de una misoginia generalizada, cuya consecuencia se hace notoria en la falta de personajes femeninos auténticos. Este tipo de caracterización no solo conduce a distorsionar la verdadera identidad de la mujer, sino que simultáneamente distrae e impide que se tome conciencia de la verdadera condición social de la mujer.

Es evidente que la aportación avellanedina entronca con el proyecto revisionista de la literatura feminista que tiene por objeto no solo cuestionar los presupuestos heroicos del discurso, sino también desfamiliarizar los hábitos de lectura con el fin de producir nuevos códigos de lectura. La meta de Avellaneda radica en formar lectores y lectoras que tengan conciencia de las prácticas sexistas de la sociedad. Aunque las mujeres victimizadas en los textos analizados no son exclusivas de la obra avellanedina, sí se encadenan con la ficción de escritoras de otros tiempos y de otros espacios. Estos puntos de contacto no constituyen el simple consenso de prácticas literarias, sino que son índices de la universalidad de la opresión de la mujer. La reiteración de la victimización del referente mujer convalida la historicidad de la literatura, sistema que relaciona el texto literario con la textura social. Aunque ya en el siglo XXI nos encontramos en vías de reescribir la historia de la mujer de modo que incorpore su contribución a la cultura, es evidente que queda aún mucho por rescatar y revisar antes de que se tenga un concepto más o menos lógico de lo que es la historia de la mujer.

La retórica estratégica de Avellaneda cuestiona los cánones literarios de mero dominio masculino. La autora sugiere estrategias para las escritoras que tratan de penetrar en el mundo literario masculino, y que por necesidad, desestabilizan y subvierten las tradiciones existentes. Por esta razón, estos esfuerzos deben estar en código lingüístico, descifrable solo para aquellos que están buscando una voz alternativa. A medida que Avellaneda desarrolla una fuerte ego-identidad como escritora y como mujer a lo largo de su trayectoria literaria, logra expresar una voz auténticamente femenina, que habla de su condición de mujer en la cultura, mientras que trasciende meros parámetros socio-culturales. Las conclusiones de este estudio se resumen en la siguiente cita de Nara Araújo: "No se trata solamente de leer a las escritoras para (re) descubrirlas y promoverlas, sino de preguntarse de qué manera el poder se ejerce o se tolera, se sufre o se transgrede, en el espacio textual" (Araújo, 1997, p. 11). En definitiva, Gertrudis Gómez de Avellaneda representa una importante contribución al conocimiento de la literatura femenina y ocupa un espacio indiscutible en el canon de la literatura hispánica del siglo XIX y en la historia del pensamiento feminista.

\section{AGRADECIMIENTOS}

Este artículo se ha realizado dentro del marco de los proyectos que dirijo como Investigadora Principal (RYC-2009-04838) y Plan Nacional I+D (FFI201239645), que han sido concedidos y financiados respectivamente por el Ministerio de Ciencia e Innovación y el Ministerio de Economía y Competitividad. 
1 Esta correspondencia finalizó cuando Cepeda se casó con otra mujer, y Avellaneda comprendió que lo había perdido para siempre. Estas cartas no fueron escritas con la intención de ser publicadas, y se suponía que el destinatario debía quemar los textos una vez leídos, pero fueron conservados y publicados por la viuda de Cepeda un año después de su muerte en 1907.

2 La trayectoria literaria de Avellaneda abarcó un período de treinta años, des-

\section{BIBLIOGRAFÍA}

Agosín, M. (1984). Rosario Castellanos ante el espejo. Cuadernos Americanos, 253, pp. 219-226.

Araújo, N. (1991). La Avellaneda, la Merlín, una manera de ser y de sentir. Excelsior, 238, pp. 53-59.

Araújo, N. (1996). La autobiografía de la Avellaneda: una estrategia de conquista. Homines, 19, pp. 357-362.

Araújo, N. (1997). Primeras palabras. En: El alfiler y la mariposa. La Habana: Editorial Letras Cubanas.

Caballero, F. (1922). Epistolario de Fernán Caballero. Barcelona: Sucesores de Juan Gili.

Cruz, M. (1973). Gertrudis Gómez de Avellaneda y su novela Sab. La Habana: Unión.

Fuss, D. J. (1989). 'Essentially Speaking': Luce Irigaray's Language of Essence, $\mathrm{Hy}$ patia, 3, pp. 63-80.

Gilbert, S. M. y Gubar, S. (1979). The Madwoman in the Attic: The Woman Writer and the Nineteenth-Century Literary Imagination. New Haven, London: Yale University Press.

Gold, J. N. (1989), The Feminine Bond: Victimization and Beyond in the Novels of Gertrudis Gómez de Avellaneda, Femeninas, 15 , pp. 83-90.

Gómez de Avellaneda, G. (1842). Dos mujeres. Madrid: Gabinete Literario.

Gómez de Avellaneda, G. (1860). Álbum cubano de lo Bueno y lo Bello (Revista quincenal de moral, literatura, bellas artes y modas). La Habana: Imprenta del Gobierno y Capitanía General.

Gómez de Avellaneda, G. (1869-1871). Obras. Madrid: Imprenta y Estereotipia de M. Rivadeneyra. de la publicación de su primera novela Sab (1841) hasta la compilación y edición de sus Obras literarias (1869-1871). Fue una intelectual y una escritora prolífica, publicando numerosos libros de poesía, seis novelas, varias obras de teatro, una colección de breves relatos (Leyendas) y dos series de ensayos periodísticos sobre la mujer titulados "La mujer" y "Galería de mujeres célebres".

3 El reconocimiento de una agenda feminista como una sub-corriente impor-

Gómez de Avellaneda, G. (1914). Autobiografía y cartas (hasta ahora inéditas) de la ilustre poetisa Gertrudis Gómez de Avellaneda, con un prólogo y una necrología de L. Cruz de Fuentes (2 ${ }^{a}$ ed.). Madrid: Imprenta Helénica.

Gómez de Avellaneda, G. (1973). Sab. La Habana: Instituto Cubano del Libro.

Irigaray, L. (1993). Sexes and Genealogies. New York: Columbia University Press.

Irigaray, L. (1996). This Sex Which Is Not One. Ithaca: Cornell University Press.

Kirkpatrick, S. (1989a). Gertrudis Gómez de Avellaneda, Carolina Coronado y Rosalía de Castro: estudios recientes. Insula, 44 , pp. $12-13$.

Kirkpatrick, S. (1989b). Las románticas. Women Writers and Subjectivity in Spain, 1835-1850. Berkeley: University of California Press.

Kirkpatrick, S. (1991). Las Románticas. Escritoras y subjetividad en España. Madrid: Cátedra.

Martí, J. (1975). Tres libros. Poetisas americanas. Carolina Freyre, Luisa Pérez, la Avellaneda. En: Obras completas, (2 ed., tomo VIII). La Habana: Editorial de Ciencias Sociales, pp. 309-313.

Miller, B. (1983). Gertrude the Great. Avellaneda, Nineteenth-Century Feminist. En Miller, B. (ed.). Women in Hispanic Literature. Icons and Fallen Idols. Berkeley, Los Angeles, London: University of California Press, pp. 201-214.

Moi, T. (1985). Sexual/Textual Politics: Feminist Literary Theory. London: Routledge.

Morales, M. (1995). Sab: La subversión ideológica del discurso femenino en la novela tante en la obra de Avellaneda ha desembocado en la publicación de varios estudios, en su mayoría, curiosamente, escritos por mujeres, y casi todos ellos empezaron a publicarse en la década de los noventa (ver Pastor, 1994, 1998, 1995a, 1995b, 1997, 1998a, 1998b, 2000a, 2000b, 2002, 2003, 2004, 2012 y 2014; Morales, 1995; Picón Garfield, 1993; Araújo, 1991; Kirkpatrick, 1989b; Gold, 1989 y Sommer, 1988).

cubana del siglo XIX. Revista de Literatura Hispanoamericana, 31, pp. 51-60.

Pastor, B. (1994). La dualidad cubano-española en el desarrollo feminista de Gertrudis Gómez de Avellaneda. En: Durnerin, J. y Ginesta, J. M. (eds). L'AmériqueLatine en Europe aux XIX et XX siecles. Orleans: Université d'Orleans/Centre Charles Péguy, pp. 247-254.

Pastor, B. (1995a). Cuba's Covert Cultural Critic: The Feminist Writings of Gertrudis Gómez de Avellaneda. Romance Quarterly, 43, pp. 178-189. http://dx.doi.org/ 10.1080/08831157.1995.10545131

Pastor, B. (1995b). Una feminista cubanoespañola: Gertrudis Gómez de Avellaneda ante la sociedad de su tiempo. ACIS: Journal of the Association for Contemporary Iberian Studies, 8, pp. 57-62.

Pastor, B. (1998). A Romantic Life in Novel Fiction: The Early Career and Works of Gertrudis Gómez de Avellaneda. Bulletin of Hispanic Studies, LXXV, pp. 169-181. http://dx.doi. org/10.1080/000749098760098229

Pastor, B. (1997). Historia del feminismo en la Cuba del siglo XIX: Gertrudis Gómez de Avellaneda, periodista avant la lettre. En: Fisher, J. (ed.). Actas seleccionadas: XI Congreso Internacional de AHILA (International Association of Historians in Latin American Studies) (vol. II). Liverpool: The Institute of Latin American Studies, University of Liverpool, pp. 535-547.

Pastor, B. (1998a). Gertrudis Gómez de AveIlaneda y sus artículos 'La mujer'. En: Almeida, J. de (ed.). Caminhos da História da America no Brasil. Brasília: ANPHLAC (Associação Nacional de Pesquisadores de História Laino-Americana e Caribenha), pp. 291-303. 
Pastor, B. (1998b). Influencia de los ilustrados Montesquieu y Rousseau en el pensamiento liberal de la escritora cubana. En: Salafranca, J. F. (ed.). Actas del II Congreso Internacional de Hispanistas. Málaga: Editorial Algazara, pp. 549-567.

Pastor, B. (2000a). Gertrudis Gómez de Avellaneda: ¿Cubana, española o simplemente una mujer? Lenguaje y Textos, 15, pp. 117-124.

Pastor, B. (2000b) Identidad femenina en el Cuadernillo autobiográfico de una escritora cubana. Revista de la Biblioteca Nacional José Martí, 1-2, pp. 89-97.

Pastor, B. (2002), El discurso de Gertrudis Gómez de Avellaneda: Identidad femenina y Otredad. Alicante: Centro de Estudios Iberoamericanos Mario Benedetti / Universidad de Alicante.

Pastor, B. (2003). Fashioning Cuban Feminism and Beyond. New York, Oxford: Lang.
Pastor, B. (2004). Discurso identitario femenino en la novela Dos mujeres de Gertrudis Gómez de Avellaneda. Revista de Estudios Hispánicos, 20, pp. 25-43.

Pastor, B. (2012). Gertrudis Gomez de Avellaneda: Cuban Nineteenth-century Literature and Feminist Thought. En: Pastor, B. M. y Davies, L. H. (eds.). A Companion to Latin American Women's Writing. London: Boydell \& Brewer-Tamesis, pp. 37-55.

Pastor, B. (2014). Más allá del canon: El caso de Gertrudis Gómez de Avellaneda. En: Garrido Gallardo, M. Á. (dir.). La Biblioteca de Occidente en el contexto hispánico. Nueva Revista, 148, pp. 361-377.

Picón Garfield, E. (1993). Poder y Sexualidad: El discurso de Gertrudis Gómez de Avellaneda. Amsterdam, Atlanta: Rodopi.
Sommer, D. (1988). Sab c'est moi. Genders, 2, pp. 111-126.

Showalter, E. (1977). Literature of Their Own. Princeton, New Jersey: Princeton University Press.

Whitford, M. (1991a). Luce Irigaray: Philosophy in the Feminine. London, New York: Routledge.

Whitford, M. (ed.) (1991b). The Irigaray Reader. Oxford: Blackwell.

Zatlin Boring, P. (1981). Una perspectiva feminista sobre la confesión de Avellaneda. En: Cabrera, R. M. y Zaldívar, G. B. (eds.). Homenaje a Gertrudis Gómez de Avellaneda. Memorias del simposio en el centenario de su muerte. Miami: Universal, pp. 93-110. 